\title{
Correction to: Functional recovery after two-stage short-interval revision of chronic periprosthetic knee joint infection
}

\author{
Tomislav Madarevic ${ }^{1,2} \cdot$ Antea Buterin $^{1,3} \cdot$ Josko Jelicic $^{4} \cdot$ Luka Sirola $^{5} \cdot$ Darinka Vuckovic $^{2}$
}

Published online: 29 July 2020

(C) SICOT aisbl 2020

\section{Correction to: International Orthopaedics} https://doi.org/10.1007/s00264-020-04566-1

The published online version contains mistake.

Reason: Authors first name and family names are mixed up.

\begin{tabular}{ll}
\hline First name & Last name \\
\hline Tomislav & Madarevic \\
Antea & Buterin \\
Josko & Jelicic \\
Luka & Sirola \\
Darinka & Vuckovic \\
\hline
\end{tabular}

Publisher's note Springer Nature remains neutral with regard to jurisdictional claims in published maps and institutional affiliations.

The online version of the original article can be found at https://doi.org/ 10.1007/s00264-020-04566-1

Tomislav Madarevic

tomislav.madjarevic@gmail.com

1 University Hospital for Orthopaedic Surgery Lovran, Lovran, Croatia

2 Medical School University of Rijeka, Rijeka, Croatia

3 Special Orthopaedic Hospital Biograd na Moru, Biograd na Moru, Croatia

4 University Hospital "Sveti Duh", Zagreb, Croatia

5 Special Hospital for Orthopaedic Surgery "Dr. Nemec", Matulji, Croatia 